\title{
A RELEVÂNCIA DA TRADUÇÃO PEDAGÓGICA PARA O DESENVOLVIMENTO DA EDUCAÇÃO BILÍNGUE NA COSTA RICA ${ }^{1}$
}

The Relevance of Pedagogical Translation for the Development of Bilingual Education in Costa Rica

\author{
Ruth Cristina HERNÁNDEZ-CHING - Universidade Nacional Heredia, Costa Rica \\ Tradução de Fernanda Cristina LOPES - UFPR
}

\begin{abstract}
RESUMO: O artigo propõe uma reflexão sobre o bilinguismo na Costa Rica à luz das últimas versões dos documentos da educação costa-riquenha (2011, 2013, 2015 e 2017). Analisam-se as contribuições bem-sucedidas de várias pesquisas nacionais e internacionais, onde a tradução pedagógica é proposta como uma técnica eficaz para o desenvolvimento de competências comunicativas. Da mesma forma, faz-se um relato dos principais marcos históricos da tradução no ensino de segunda língua. Existem importantes programas no MEP (Ministério de Educação Pública), escolas, colégios e universidades públicas e privadas, mas há uma tendência a associar o uso da tradução ao ensino apenas via método gramatica-tradução. Estudos posteriores poderiam comparar o desenvolvimento entre estudantes que adquiriram o idioma como segunda língua e trabalharam por um curto período de tempo em um centro de atendimento, em turismo ou em atividades da vida real em que precisaram traduzir ou interpretar em modo real, em comparação com aqueles que não o fizeram.
\end{abstract}

PALAVRAS-CHAVE: tradução; competências; educação bilíngue; ensino de inglês

ABSTRACT: The article reflects on bilingualism in Costa Rica in recent years in light of the latest versions of the Reports on the Costa Rican Public School Systems (2011, 2013, 2015 y 2017). Successful contributions of several national and international researches, where teaching translation as effective technique for developing communication skills is proposed, are discussed. Also, the article reviews major historical landmarks of translation in second language teaching. There are programs in the Ministry of Public Education (MEP), public and private colleges, schools and universities, but there is a tendency to associate the use of translation in teaching only with the grammatical method. Later studies could be oriented to compare the progress between populations that have acquired the language as a second language and have worked for a short period of time in a call center, in tourism, or in real life activities where they have to translate or interpret in real mode, compared to those that do not.

KEYWORDS: translation; competences; bilingual education; english teaching.

\section{INTRODUÇÃO}

No marco dos debates que surgem em torno da negociação do Convênio do Fundo Especial para a Educação Superior (FEES), Vargas (2014), professor da

\footnotetext{
${ }^{1}$ Artigo publicado originalmente em língua espanhola na Revista Eletrônica Educare, vol.23, 2019. ISSN: 1409-4258. Disponível em:

<< http://revistas.una.ac.cr/index.php/EDUCARE/article/download/8711/13892/>>
} 
Universidade da Costa Rica, argumenta que o desenvolvimento bem-sucedido das universidades públicas dependerá da fidelidade às origens e objetivos para os quais foram criadas. Do mesmo modo, enfatiza que a educação universitária pública deve garantir que os estudantes universitários graduados consigam se inserir na dinâmica social com ferramentas que permitam um desenvolvimento integral (VARGAS, 2014). Ao interpretar essas palavras, pode-se afirmar que as universidades devem responder às necessidades que a sociedade apresenta.

Se contrastarmos essa opinião com o "Sexto Relatório do Estado da Educação" (PROGRAMA ESTADO DA NAÇÃO, 2017), poderíamos dizer que, para os efeitos práticos desta pesquisa, na área de inglês é possível questionar essa abordagem quanto à eficácia de ingresso dos grupos graduados ao mercado de trabalho. Caso ingressem, o “Terceiro Relatório do Estado da Educação" (PROGRAMA ESTADO DA NAÇÃO, 2011) mostra que há possibilidade de melhorias no currículo de inglês, especialmente no ensino médio, como o trecho do supracitado relatório a seguir evidencia ao apontar que, apesar das mudanças, apenas $10 \%$ da população tem uma segunda língua:

Nos últimos anos, a Costa Rica passou por grandes mudanças em sua estrutura econômica, que exigiram a reorientação de requisitos técnicos e de formação em algumas áreas específicas, como o uso instrumental de informática e o desenvolvimento de conhecimentos e habilidades na língua inglesa. (p. 136)

O “Terceiro Relatório do Estado da Educação" aponta que o estudo "Avaliação Nacional de Inglês" da Fundação Costa Rica Multilíngue, mediu o nível de conhecimento de inglês em vários setores durante 2012. Os resultados da avaliação situam os alunos das escolas públicas no nível A2 do Quadro Comum Europeu, os do Instituto Nacional de Aprendizagem (INA) no nível A2, os de universidades públicas no nível B1 e os de escolas técnicas no nível A1. Entre os desafios apresentados por esse estudo, está avaliar a possibilidade de reproduzir as práticas que são obtidas em materiais de segundas línguas em escolas privadas porque, ao classificar esse grupo e compará-lo com as escolas públicas, ele obteve, em média, um nível B2. Segundo o mesmo documento, as empresas transnacionais exigem o nível $\mathrm{C} 1$ (avançado), que é a média que essas empresas solicitam para recrutar pessoal (PROGRAMA ESTADO DA NAÇÃO, 2011). Portanto, um dos desafios do próximo governo será reavaliar a oferta acadêmica para o pessoal técnico para que "a educação responda à oferta de trabalho" (OVIEDO, 2014, p. 8). O "Quarto Relatório do Estado da Educação" indica que, em comparação com o ano 2000, $10 \%$ da população de 18 anos é fluente em inglês, o que 
mostra um avanço lento em comparação com aquele ano (PROGRAMA ESTADO DA NAÇÃO, 2013). Em relação ao "Quinto Relatório do Estado da Educação" (PROGRAMA ESTADO DA NAÇÃO, 2015), aclara-se que a oferta dessa língua foi ampliada e que as iniciativas para oferecê-la na educação técnica foram expandidas. Da mesma forma, destaca-se o fato de que mais professores jovens foram incorporados ao ensino dessa língua, juntamente com um importante impulso para novas metodologias que caminham junto com as tecnologias. Além disso, o "Quinto Relatório do Estado da Educação" explica que, de acordo com o Plano Nacional de Desenvolvimento 20152018, o objetivo é garantir a universalização de uma segunda língua e, para 2018, o ensino do inglês aumentaria para 90\% na educação primária (PROGRAMA ESTADO DA NAÇÃO, 2015). Por fim, o "Sexto Relatório do Estado da Educação" (PROGRAMA ESTADO DA NAÇÃO, 2017), indica que embora a oferta, incluindo as lacunas, tenha sido ampliada, observa-se que ainda há um domínio baixo da língua, não só entre o corpo discente, mas também entre o docente:

\begin{abstract}
Embora o ensino de uma segunda língua, como o inglês, tenha começado no sistema educacional no século passado, vinte anos depois, as conquistas não tiveram a qualidade ou o ritmo de progresso esperados. Apesar de cursar essa matéria desde a pré-escola, a maioria dos alunos não consegue lidar com a língua depois de sair da escola. (PROGRAMA ESTADO DA NAÇÃO, 2017, p. 166)
\end{abstract}

Ao conhecer essa realidade, esta pesquisa pretende lançar luz sobre as estratégias pedagógicas universitárias que poderiam contribuir para um melhor desempenho das habilidades comunicativas. Essa melhoria seria alcançada por meio da formação de professores de ensino médio e superior, que seriam agentes de mudança, respondendo às necessidades educacionais imediatas.

No âmbito internacional, no "Informe de Acompanhamento da EPT no Mundo" 2013/2014, a UNESCO (2014) comenta sobre a melhoria no ensino de segundas línguas que:

Políticas linguísticas podem ser difíceis de aplicar, especialmente quando há mais de um grupo linguístico na mesma sala de aula e o professor não domina a língua vernácula. Para que a educação bilíngue seja eficaz, os governos devem contratar e distribuir adequadamente professores de grupos linguísticos minoritários. Programas iniciais e duradouros também são necessários para formar docentes que possam ensinar em dois idiomas e compreender as necessidades dos alunos que estudam em uma segunda língua. (p. 56) 
Como se pode perceber com essa afirmação, vários elementos devem ser considerados para desenvolver a proficiência linguística, como fornecer ao sistema nacional de educação pessoal docente capacitado não apenas na língua meta, mas também na língua materna.

Diante desse panorama, o "Terceiro Informe do Estado da Educação" levanta as seguintes questões: "Como garantir que os professores de inglês dominem com qualidade habilidades linguísticas e pedagógicas? Como resolver o problema de designação de pessoal docente temporário que não cumpre adequadamente com os padrões? É necessário mudar a avaliação do quinto ano, que tem um enfoque de compreensão de leitura e múltipla escolha, a uma avaliação que meça as habilidades comunicativas?" (PROGRAMA ESTADO DA NAÇÃO, 2011). Como educadores e educadoras do idioma, devemos nos informar sobre a realidade contemporânea para sermos sujeitos participantes ativos das necessidades imediatas e repensarmos, se necessário, nosso trabalho sem perder as reformas educacionais de vista.

\section{ANTECEDENTES}

Diversas fontes nacionais e internacionais de caráter empírico contribuem com experiências para a temática deste artigo. A seguir, cada uma delas será apresentada, indicando o tipo de trabalho realizado, seus autores, os aspectos metodológicos relevantes, as descobertas relevantes e suas principais conclusões. Com o objetivo de compreender a nomenclatura utilizada, deve-se ter em mente que o termo bilíngue ou multilíngue é conceituado como "o uso de dois ou mais idiomas como vetores de ensino" (UNESCO, s/d, p.2). Por outro lado, o termo tradução pode ser definido como uma atividade inteligente que envolve diferentes processos de aprendizagem consciente e inconsciente (ROBINSON, 1997).

A primeira fonte consultada, "La historia de la traducción: su importancia para la traductología y su enseñanza mediante un programa didáctico multimedia y multilingüe" corresponde a Delisle, teórico canadense de estudos da tradução da Universidade de Otawa. Delisle (2003) explica a importância de incorporar matérias sobre história da tradução em currículos de ensino de línguas e de tradução para compreender suas "funções históricas, assim como alguns dos diferentes subtemas de pesquisa" (p. 221). Para o autor, conhecer os marcos da história da tradução como prática de comunicação retransmitida em termos pedagógicos permite: (a) melhorar a 
compreensão do trabalho do aluno, uma vez que é possível compreender o histórico, (b) ampliar a flexibilidade intelectual ao conhecer contribuições e pontos de vista diferentes, (c) promover tolerância com as várias formas de lidar com problemas idiomáticos e (d) compreender a tradição no pensamento e práticas divergentes. Por outro lado, ao apreender as funções históricas da tradução que abriram, em linhas gerais, portas para a produção do "outro", abrem-se portas para diferentes mundos por meio da função instrumental e mediadora da tradução. Delisle (2003) explica algumas das funções da tradução: genética, estilística, literária, formativa, identitária, paliativa, democrática e mediadora.

Do mesmo modo, os estudos da história da tradução permitem propor tarefas específicas e novos campos de tradução, já que o aluno tem a possibilidade de se tornar um "historiador da tradução" ao entender e justificar suas decisões linguísticas porque ele tem a habilidade de se aprofundar na maneira de melhorar sua produção. A partir da perspectiva de Delisle (2003), é possível justificar este trabalho de pesquisa e realizar uma proposta no que se refere à necessidade de aprofundamento das estratégias de aprendizagem de uma língua estrangeira por meio da tradução, e até mesmo linhas de pesquisa sobre a evolução da tradução por meio da psicopedagogia poderiam ser consideradas.

A segunda fonte corresponde ao artigo "Schema activation in translation and reading: A paradoxical effect", de Macizo e Bajo (2009), publicado na Revista Psicológica da Universidade de Granada, Espanha. Nesse texto, os autores examinam a ativação de esquemas de tradutores profissionais que leem e traduzem, simultaneamente, ou leem em voz alta na presença de textos. Segundo a pesquisa, a leitura é uma técnica eficaz para desenvolver a memória; de fato, é necessária em todos os níveis de representação a nível lexical, de oração e processos de acordo com o nível do texto e para reter as informações necessárias durante o processo de leitura. Essa capacidade de memória a partir da leitura de textos, embora limitada, permite uma melhor compreensão dos idiomas, não apenas do próprio, mas também de outros. Ao revisar as referências na supracitada pesquisa, há estudos que mostram que a leitura desempenha um papel crucial no desenvolvimento da interpretação simultânea e tradução, nos estudos bilíngues e na aquisição de línguas estrangeiras. Em suma, as referências consultadas nesse estudo indicam que a produção oral de intérpretes melhora significativamente por terem lido previamente os tópicos a serem abordados. 
Uma vez que as bases teóricas são conhecidas, as pesquisadoras explicam que se trata de uma pesquisa exploratória e empírica do uso de estratégias para demandas de memória de trabalho na tradução e na leitura. Para a pesquisa, três experimentos foram realizados. No primeiro experimento, a compreensão de texto melhorou quando um resumo da leitura foi apresentado às pessoas participantes antes de que lessem em voz alta. No entanto, a apresentação prévia do resumo reduziu a compreensão quando os participantes tiveram que realizar uma tradução oral à prima vista. No experimento dois, o mesmo resultado foi obtido quando a tradução semiconsecutiva foi feita. No terceiro experimento, quando os sujeitos participantes trabalharam com a melhoria operante, $\mathrm{o}$ uso de um resumo não agregou qualquer valor à tradução. Como método dessa pesquisa, o trabalho foi realizado com dez tradutores profissionais que traduziram do espanhol ao inglês. Uma das conclusões mais valiosas do experimento foi a necessidade de desenvolver as habilidades de memória dos aprendizes quando eles têm que interpretar pois, de acordo com essa pesquisa, a leitura prévia do material a ser interpretado não facilita necessariamente a produção oral quando se interpreta.

O terceiro estudo consultado foi o trabalho de mestrado desenvolvido por Escobar (2011), "La traducción como herramienta para la enseñanza-aprendizaje de idiomas (Caso de colegios técnicos-profesionales de Ministerio de Educación Pública)" da Universidade Nacional da Costa Rica, durante 2008. Esse estudo visa fornecer uma pauta para melhorar o ensino de inglês nas escolas técnicas do país, de acordo com as declarações do pessoal de recursos humanos de empresas transnacionais que não recrutam uma alta porcentagem de estudantes graduados porque seu nível de inglês não alcança o nível exigido. A partir dessa realidade, Escobar (2011) realiza seu trabalho de pesquisa em três colégios técnicos, onde corrobora que a tradução é usada para ensinar ou avaliar o inglês; no entanto, o corpo docente que ministra os cursos não tem preparação formal em estratégias de ensino de tradução. A pesquisadora considera apropriado repensar o papel da tradução nos programas de ensino de inglês nos colégios técnicos profissionais do MEP (Ministério de Educação Pública). Posteriormente, fornece uma retrospectiva histórica da maneira como a tradução foi usada mais como uma ferramenta e não como um método de ensino. A metodologia utilizada foi primeiro determinar, por meio do Plan Maestro do PLANICIT (Plano Nacional de Capacitação em Inglês), a oferta de cursos de tradução para o ensino de inglês em escolas técnicas. 
A partir disso, foram selecionadas três escolas do Valle Central e os professores e alunos foram entrevistados. A partir dos resultados obtidos, conclui-se que os professores que ministram os cursos não dominam o inglês e que essa também não é sua área de especialização. Por outro lado, também conclui-se que o método comunicativo não é utilizado, como sugerido nos programas. Posteriormente, utilizando a escala Likert, o aluno foi consultado sobre como ele gosta de aprender as quatro habilidades básicas do inglês e como ele considera que a tradução contribui nesse processo formulando os critérios de acordo com teorias pedagógicas e de ensino de línguas estrangeiras. Posteriormente, os dados foram tabulados usando o programa de computador SPSS (Statistical Package for the Social Science). Em seguida, com base nos resultados das pesquisas, uma série de estratégias pedagógicas que podem ser utilizadas nas turmas de inglês de escolas técnicas em termos de tradução foi apresentada. Uma das conclusões do trabalho é a necessidade de capacitar os professores de inglês em métodos de tradução para o desenvolvimento das quatro habilidades de comunicação. Por outro lado, a tradução como método de ensino de línguas estrangeiras perdeu popularidade juntamente com o método gramática-tradução, o que implica em um desafio para demonstrar que, juntamente com os avanços nas teorias de tradução, o ensino desta disciplina evoluiu e promete ser um grande aliado na educação costarriquenha.

O quarto trabalho corresponde ao desenvolvido por Domian (2007), vicediretora da Escola de Literatura e Ciências da Linguagem da Universidade Nacional, que se intitula "Proficiency guidelines to determine levels of communicative translation competence in translation training" (2007). A supracitada pesquisa foi realizada no programa de Mestrado em Tradução Inglês-Espanhol da Universidade Nacional, com o objetivo de criar escalas para medir a competência funcional dos alunos do referido programa de estudos. No marco teórico desta pesquisa realiza-se uma revisão do modo como a tradução foi avaliada nos últimos dez anos. Como parte da metodologia, o Conselho Americano para o Ensino de Línguas Estrangeiras (ACTFL, por sua sigla em inglês) e o Quadro Comum Europeu de Referência para as Línguas, entre outros, foram tomados como pontos de referência. Em seguida, foram criados descritores a partir de traduções feitas por alunos de diversos níveis do programa, de tradutores profissionais e empíricos e de pessoas bilíngues. O resultado da pesquisa foi o desenho de uma escala para a mensuração das seguintes competências: comunicativa da língua em tradução, de 
transferência, estratégica e cultural; essas escalas podem ser usadas individualmente ou globalmente ao avaliar as traduções.

Os estudos descritos acima propõem ideias sobre eventuais categorias de pesquisa; do mesmo modo, suas principais conclusões são úteis em termos de pontos de partida da supracitada pesquisa. Além disso, têm grande valor, já que foram pesquisas realizadas no Canadá, na Espanha e na Costa Rica, o que permite, eventualmente, comparar seus resultados em contextos semelhantes aos da Costa Rica contemporânea. Com base no exposto, pode-se argumentar que esses trabalhos representam contribuições valiosas para tornar visível a importância da tradução pedagógica.

\section{Da TRAduÇÃo PEdAgógica E SUA LigaÇÃo COM A EDUCAÇÃo BILÍNGUE}

Agost (2008) define o ensino da tradução como um processo construtivista que evolui no ritmo dos avanços do ensino e, portanto, percebe o ensino da disciplina em movimento dinâmico mediado por métodos pedagógicos ativos, distantes da memorização e do não significativo, onde os significados e novos conhecimentos são negociados vertical e horizontalmente. Da mesma forma, conceitua o termo didática da tradução como um processo heurístico, onde o percurso não é menos importante que o fim. O ensino da tradução encontra-se rodeado por uma nuance holística, já que incorpora avanços culturais, psicopedagógicos, linguísticos e tecnológicos. Por outro lado, experiências transacionais são propostas e construídas entre membros dos grupos (dentro e fora do contexto educacional) e professores que incorporam tendências cognitivistas, funcionalistas e socioconstrutivistas (BAUMGARTEN; KLIMKOWSKI; SULLIVAN, 2010).

De maneira distinta, Agost (2008) compartilha uma série de competências que, à sua maneira, devem ser promovidas no ensino da disciplina: capacidade de análise e síntese; capacidade de organizar e planejar; motivação pela qualidade, iniciativa e espírito empreendedor; resolução de problemas; raciocínio crítico; aprendizagem autônoma; conhecimento do mercado de trabalho, aquisição de conhecimentos teóricos, variedades de tradução e habilidades de tradução.

Delisle (1988) sintetiza a tradução pedagógica como uma interação constante com o texto para alcançar o equilíbrio entre a detecção da ambiguidade em termos linguísticos (erros ou aspectos a serem melhorados) e os elementos positivos. Hernández (1996) percebe-a como a atividade didática onde a manipulação, a análise 
contrastiva e a reflexão dos discursos entram em ação com o objetivo de melhorar a língua meta.

Pintado (2012), por sua vez, define tradução pedagógica como o encontro entre conhecimento e avanços no desenvolvimento da tradução como disciplina. Resgata a importância da tradução no ensino de línguas estrangeiras, já que, a partir de seu ponto de vista, facilita o desenvolvimento da competência comunicativa, uma vez que combina teoria e prática. Pintado (2012) sustenta sua posição com a contribuição de vários teóricos, tais como Delisle, que em 1984 cunhou o termo tradução comunicativa; Snell-Hornby, que em 1988 falou de tradução como comunicação entre culturas e Newmark, que em 1981 introduziu e combinou os termos tradução semântica e tradução comunicativa. Ao mesmo tempo, ela lembra que a tendência atual no que tange à pedagogia da tradução é a combinação de competência e ensino comunicativo que reúne o uso da linguagem, onde as estruturas semânticas foram internalizadas, em situações particulares.

Gierden (2003) define a pedagogia da tradução como um exercício integrador, cujas valiosas contribuições no campo da educação foram ofuscadas pela atmosfera criada em torno da didática do ensino de línguas clássicas, com um método de memorização muito criticado. $\mathrm{O}$ ensino da tradução também pode ser definido como um recurso valioso para o ensino de uma língua, que, apesar de seus contra-argumentos, tem fundamento e validade cientificamente comprovada como um processo.

Olvera et al. (2004) entendem o processo de ensino-aprendizagem como aquele em que, de modo sequencial, várias tarefas são organizadas e onde cada aluno, como membro de uma equipe, aplica conhecimentos, competências (formadas por subcompetências e divididas de modo mais particular em habilidades) e habilidades adquiridas nas matérias que cursa, cumprindo uma função essencial para o seu conjunto (OLVERA et al., 2004). Por outro lado, no que diz respeito ao ensino da tradução, Lazo e Zachary (2008) expressam que ela consiste em transmitir um saber fazer, e mais importante do que transmitir conhecimento é desenvolver nos alunos a capacidade de adquiri-los e processá-los. Finalmente, Gasca (2017) define a tradução pedagógica como "o uso da tradução como ferramenta didática para facilitar o ensino e a aquisição de línguas".

Embora as definições anteriores sejam encorajadoras e inspiradoras no que diz respeito ao termo pedagogia ou ensino de tradução, ainda existe uma concepção 
amplamente difundida de que a disciplina é antiquada, entediante e pouco eficaz no ensino de processos comunicativos, e para esse caso particular, da produção oral. Ao consultar o material bibliográfico, a bibliografia ainda a enquadra dentro de um modelo de ensino obsoleto. Por exemplo, Von Gleich (1993) menciona que com a chegada do método direto "a tradução é rejeitada e centram-se [...] na produção oral" (p. 48). O mesmo pode ser lido no livro "Approaches and methods in language teaching" (2001) de Richards e Rodgers, quando comentam que, a partir do movimento de reforma, o estudo da língua falada torna-se prioridade e tanto o latim quanto o método gramáticatradução são descartados para motivar a produção oral no ensino e aprendizagem de segundas línguas.

\section{BENEFÍCIOS A NÍVEL COMUNICATIVO COM O ENSINO DA TRADUÇÃO}

Esta seção permite reinterpretar a tradução para além da perspectiva tradicional que a associa ao estruturalismo e à mecanização. A didática da tradução ainda está fortemente ligada à ideia de "verter" conteúdo a outra língua (NIDA; TABER, 1986) e parece difícil dissociá-la do método de ensino de latim ou grego (RICHARDS; RODGERS, 2001). Ou seja, nessa perspectiva, o ensino da tradução é percebido como o processo de memorizar palavras gramaticais e regras para aprender a língua e, assim, produzir textos, imagens ou sons. Esse ponto de vista tradicional do ensino da tradução ainda impregna os programas de estudo de nosso país, tanto no nível universitário quanto secundário.

Estudos como os de Vermeer (1986) falam de tradução não apenas como um exercício linguístico-comunicativo, mas como um processo bi e até multicultural; Hurtado (2001) oferece um ensino comunicativo da tradução. Na mesma direção, Cuéllar-Lázaro (2004) propõe um enfoque na tradução no ensino comunicativo de línguas; ou seja, considera-se que existem diversos autores e propostas teóricas que permitem à autora deste artigo fundamentar, de maneira sólida, a importância de se fazer uma mudança epistemológica e metodológica na natureza e escopo da tradução. Nessa perspectiva, Nord (2009) resgata também o valor das competências tradutórias dos aprendizes, já que permitem solucionar diversas funções comunicativas, tais como conflitos culturais, mais do que apenas decifrar as regras gramaticais de um texto.

Com os movimentos de reforma no ensino de línguas estrangeiras (RICHARDS; RODGERS, 2001), o ensino da tradução encontra novos horizontes. Além disso, com os 
avanços na área da psicopedagogia, cenários esperançosos tornam-se possíveis, nos quais a tradução pode contribuir no que diz respeito ao ensino de habilidades comunicativas. A partir da evolução da abordagem funcional e da didática da tradução torna-se possível falar sobre as competências culturais básicas que permitem a habilidade de comunicação em contextos tanto na língua fonte quanto na meta (BAKER, 2001). O bilinguismo e, portanto, as transações de tradução e interpretação, proporcionam benefícios no sistema linguístico e comunicativo da língua materna e da língua estrangeira do aluno, melhoria nos processos de interlíngua e de interculturalidade, apropriação da competência discursiva e textual e desenvolvimento do papel como mediador comunicativo e cultural implícita e explicitamente.

\section{CONCLUSÕES}

Existem importantes programas no MEP (Ministério de Educação Pública), colégios, escolas públicas e privadas; no entanto, a tendência de associar o uso da tradução ao ensino apenas pelo método gramática-tradução persiste. Os resultados desta pesquisa bibliográfica defendem a revalidação da tradução pedagógica nos contextos de planejamento e produção dos programas de ensino de línguas da Costa Rica para fortalecer o trabalho do corpo docente de escolas técnicas e profissionalizantes públicas, já que, de acordo com todos os relatórios de educação, ainda que a oferta educacional seja ampliada, há indicativos de que a produção ou o output dos alunos não atinge os níveis desejados. Dada a sua evidente relevância social nacional atual e o alto potencial que oferece para desenvolver futuros estudos associados ao tema - já que na Costa Rica há poucos precedentes nesse sentido -, sua articulação direta se materializou como um dos atributos mais relevantes para os professores de educação superior e média que apresentam limitações práticas, conforme destacado no último Informe do Estado da Educação. Estudos posteriores poderiam dedicar-se a comparar o progresso entre estudantes que adquiriram o idioma como segunda língua e trabalharam por um curto período de tempo em um call center, no turismo ou em atividades da vida real onde precisam traduzir ou interpretar de modo real, em comparação com aqueles que não o fazem.

Dentro do sistema educacional da Costa Rica, os programas do Ministério da Educação Pública, universidades públicas e privadas e associações profissionais têm projetos curriculares nessa área, por isso seria valioso atualizar as teorias e práticas de 
ensino e reproduzir as boas práticas das instituições onde são obtidos melhores níveis de proficiência linguística. Exemplo disso é o programa de Mestrado em Tradução da Universidade Nacional, que incorpora uma matéria optativa chamada LPA-7150, "La enseñanza de la traducción" (Universidade Nacional, 2012). Por outro lado, a autora deste artigo elaborou uma proposta para um curso virtual, já criado também no espaço da sala de aula virtual (Universidade Nacional, 2018) com essa temática com o propósito de oferecê-lo como uma extensão ou em colaboração com o COLYPRO (Colegio de Licenciados y Profesores en Letras, Filosofía, Ciencias y Artes, Costa Rica) (Anexo 1).

A redescoberta da tradução pedagógica poderia ser muito útil para que docentes universitários, de educação técnica e autoridades institucionais de cada centro de ensino implementem ações educativas e procedimentos que favoreçam a realização de atividades que promovam o fortalecimento do ensino de inglês como língua estrangeira em cada instituição. Finalmente, o ensino para o desenvolvimento das habilidades comunicativas com a integração da tradução pedagógica não só pode cumprir os requisitos de uma educação de qualidade, conforme exigido pelas normas internacionais de educação, mas também permitir que o aluno que se formou em colégios técnicos e de ensino médio em geral desenvolva seu pensamento crítico, consiga inserir-se de modo bem-sucedido no mercado de trabalho competitivo e que, no futuro, também atinja mobilidade profissional e educacional em um mundo globalizado.

\section{REFERÊNCIAS}

AGOST, Rosa. Enseñar la teoría de la traducción: diseño de competencias y explotación de recursos pedagógicos. Quaderns. Revista de Traducció, Barcelona, n. 15, p.137-152, 2008.

BAKER, Mona. (ed.) Routledge. encyclopedia of translation studies. 1 ed. New York: Routledge, 2001.

BAUMGARTEN, Stefan; KLIMKOWSKI, Konrad e SULLIVAN, Clare. Towards a transgressionist approach: Criticalreflexive translator education. Translation in Transition, 5, 2010. Disponível em: <http://www.t21n. com/homepage/articles/T21N2010-05-Baumgarten,Klimkowski,Sullivan.pdf >>

CUÉLLAR-LÁZARO, Carmen. Un nuevo enfoque de la traducción en la enseñanza comunicativa de las lenguas. Hermeneus. Revista de Traducción e Interpretación, n.6, p.41-57, 2004. 
DELISLE, Jean. Translation: An interpretative approach. Ottawa: University of Ottawa Press, 1988.

La historia de la traducción: Su importancia para la traductología y su enseñanza mediante un programa didáctico multimedia y multilingüe. Íkala, Revista de Lengua y Cultura, n.8(1), p.221-235, 2003.

DOMIAN, Catalina. Proficiency guidelines to determine levels of communicative translation competence in translation training (Dissertação de Mestrado). Universidade Nacional, Costa Rica, Heredia, 2007. Disponível em: $<$ http://www.mogap.net/pmt/CatalinaDomian.pdf $>>$

ESCOBAR, Ana Laura (2011). La traducción como herramienta para la enseñanzaaprendizaje de idiomas (Caso de colegios técnicos-profesionales de Ministerio de Educación Pública) (Dissertação de Mestrado). Universidade Nacional, Heredia, Costa Rica, 2011. Disponível em: << http://www.mogap.net/pmt/ AnaLauraEscobar.pdf>>

GASCA, Laura. Las posibilidades de la traducción pedagógica en la enseñanza del español como segunda lengua. Estudios de Lingüística Aplicada, n. 35, p.205-232, 2017. Disponível em: <<http://ela.enallt.unam.mx/index.php/ela/article/view/837>>.

GIERDEN, Carmen. La traducción pedagógica como ejercicio integrativo en la didáctica del alemán como LE. Encuentro: Revista de investigación e innovación en la clase de idiomas, n.13-14, p.90-100, 2003. Disponível em: $<<$ https://ebuah.uah.es/dspace/bitstream/handle/10017/982/La\%20Traducci\%c3\%b3n\% 20Pedag\%c3\%b3gica\%20como\%20Ejercicio\%20Integrativo\%20en $\% 201 \mathrm{a} \% 20 \mathrm{Did} \% \mathrm{c} 3$ $\%$ a1ctica\%20del\%20Alem\%c3\%a1n\%20como\%20E.pdf?sequence=1\&isAllowed=y $>>$

HERNÁNDEZ, Rosario. La traducción pedagógica en la clase de E/LE. VII Congreso Internacional de la ASELE. Centro Virtual Cervantes. Disponível em: $<<$ https://cvc.cervantes.es/ensenanza/biblioteca_ele/asele/pdf/07/07_0247.pdf >>

HURTADO, Albir. Traducción y traductología. Madrid: Cátedra, 2001.

LAZO, Rosa María e ZACHARY, Monique. La enseñanza de la traducción centrada en el estudiante. Onomázein, n.17, p.173-181, 2008. Disponível em: $<<$ http://onomazein.letras.uc.cl/Articulos/17/N1_Lazo.pdf $>>$

MACIZO, Pedro. e BAJO, María Teresa. (2009). Schema activation in translation and reading: A paradoxical effect. Psicológica, n.14, p.59-89, 2009. Disponível em: $<$ https://www.uv.es/revispsi/articulos1.09/4MACIZO.pdf>

NIDA, Eugene Albert e TABER, Charles. La traducción: Teoría y práctica. Madrid: Ediciones Cristiandad, 1986.

NORD, Christiane. El funcionalismo en la enseñanza de traducción. Mutatis Mutantis, n.2, p.209-243, 2009. Disponível em:

< https://dialnet.unirioja.es/descarga/articulo/3089531.pdf >> 
OLVERA, María Dolores (org). Aplicación de un modelo didáctico de enseñanza de la traducción. Eslavística Complutense, n.4, p.249-255, 2004. Disponível em: <<https://revistas.ucm.es/index.php/ESLC/issue/view/ESLC040411/showToc>>

OVIEDO, Esteban. (11 de abril de 2014). Luis Guillermo Solís pide ayuda a empresarios para aclarar caso Intel. La Nación, p. 8A., Política. 11 de abril de 2014. Disponível em: < < https://www.nacion.com/el-pais/politica/luis-guillermo-solis-pideayuda-a-empresarios-para-aclarar-caso-

intel/BRQJY22W7BEWPNTYWPGMMLGNLM/story/>

PINTADO, Lucía. Fundamentos de la traducción pedagógica: Traducción, pedagogía y comunicación. Sendebar, n.23, p.321-353, 2012. Disponível em: <<http://revistaseug.ugr.es/index. php/sendebar/article/view/41/41>>

PROGRAMA ESTADO DE LA NACIÓN. Tercer informe estado de la educación. San José, Costa Rica, 2011. Disponível em: $<$ http://estadonacion.or.cr/informe-iii-estadoeducacion $>>$

Cuarto informe estado de la educación. San José, Costa Rica, 2013. Disponível em: <<http://estadonacion.or.cr/informe-iv-estado-educacion $>>$

Quinto informe estado de la educación. San José, Costa Rica, 2015. Disponível em: $<<$ https://estadonacion.or.cr/educacion2015/>>

Sexto informe estado de la educación. San José, Costa Rica, 2017. Disponível em: $<<$ https://estadonacion.or.cr/educacion2017/>>

RICHARDS, Jack e RODGERS, Theodore. Approaches and methods in language teaching. New York: Cambridge University Press, 2001.

ROBINSON, Douglas. Becoming a translator. An accelerated course. Nova York:

Routledge, 1997. Disponível em:

<<https://doi.org/10.4324/9780203441138_chapter_9>>

UNESCO. Enseñanza y aprendizaje. Lograr la calidad para todos (resumo). Informe de seguimiento de la EPT en el mundo. Disponível em: <<http://unesdoc.unesco.org/ images/0022/002256/225654s.pdf>>

Día internacional de la lengua materna. Las lenguas locales para la ciudadanía mundial: La ciencia en primer plano. Disponível em: <<http://www.unesco. org/new/es/unesco/events/prizes-and-celebrations/celebrations/international-days/ international-mother-language-day-2014/>>

UNIVERSIDAD NACIONAL. La enseñanza de la traducción (LPA715-O). Plan de Maestría Profesional en Traducción Inglés-Español. Heredia: Escuela de Literatura y Ciencias del Lenguaje, 2012. 
La traducción pedagógica en la enseñanza del inglés técnico y vocacional

(Curso en aula virtual, actualización profesional). Heredia: Escuela de Literatura y

Ciencias del Lenguaje, 2018. Disponível em:

<<http://www.aulavirtualdp.una.ac.cr/course/view.php?id=916>>

VARGAS, José. Ángel. Universidades públicas y próximo gobierno. Diario Extra, p. 7, Opinión, 12 de março de 2014. Disponível em: < http://www.diarioextra.com/Noticia/detalle/227104/universidades-publicas-y-proximogobierno >>

VERMEER, Hans. Übersetzen als kultureller Transfer. Übersetzungwissenschaft-eine Neuorientierung. Tubinga: Francke, 1986.

VON GLEICH, Una. El bilingüismo - marco teórico. Pedagogía intercultural bilingüe. Fundamentos de la educación bilingüe Quito: Abya-Yaala, 1993. 


\section{ANEXO 1}

Colégio de Licenciados e Professores
Departamento de Formação Acadêmica, Profissional e Pessoal
Processo: Desenvolvimento Profisisonal
Programa da disciplina

Nome da disciplina: A tradução pedagógica no ensino de inglês técnico e profissional

Nome do professor: A definir

Sede: virtual

Horário: A definir

Duração: 40 horas (6 semanas)

Tipo de disciplina: Optativa

Justificativa

A partir da perspectiva da gramática funcional há certa rejeição ou receio da aplicação da tradução pedagógica em aulas de língua estrangeira. O objetivo dessa disciplina é redescobrir a tradução como aliada efetiva e inovadora para alcançar as competências comunicativas apresentadas no Quadro Comum Europeu de Referência para as Línguas: Aprendizagem, Ensino, Avaliação.

\section{Objetivo geral}

- Analisar o papel da tradução pedagógica como técnica que possibilita o alcance de competências comunicativas nas aulas de inglês das escolas técnicas e profissionalizantes.

\section{Objetivos específicos}

- Reconstruir o papel da tradução pedagógica à luz do Quadro Comum Europeu de Referência para as Línguas: Aprendizagem, Ensino, Avaliação.

- Reafirmar a importância de se incorporar a tradução pedagógica como aliada nos processos de ensino-aprendizagem das competências comunicativas de inglês nas escolas técnicas e profissionalizantes.

- Refletir sobre o uso da tradução pedagógica nas escolas técnicas e profissionalizantes.

- Propor técnicas de aplicação da tradução pedagógica para o desenvolvimento das competências comunicativas de inglês nas escolas técnicas e profissionalizantes.

\section{Conteúdos}

- O papel da tradução pedagógica na aquisição de línguas estrangeiras.

- O papel da tradução pedagógica à luz do Quadro Comum Europeu de Referência para as

Línguas: Aprendizagem, Ensino, Avaliação.

- O papel da tradução à luz do Estado da Educação.

- O papel da tradução pedagógica para o desenvolvimento das competências comunicativas no

ensino-aprendizagem de inglês.

\section{Atividades}

- Participar das atividades introdutórias.

- Leitura de "The Role of Pedagogical Translation in Second Language Acquisition" e

"Aplicaciones prácticas de la traducción pedagógica en la clase de ELE".

- Leitura do Quadro Comum Europeu de Referência para as Línguas: Aprendizagem, Ensino, Avaliação.

- Leitura de "Estado de la Educación".

- Leitura de "Revisión Destrezas más allá de la Escuela en Costa Rica".

- Leitura de "Pautas para la elaboración de un programa de traducción técnica básica para instituciones vocacionales". 
Cronograma (com datas de cada semana)

\begin{tabular}{|c|c|c|c|}
\hline Data & Tema & Atividade & Tarefa \\
\hline $\begin{array}{l}\text { Semana } \\
1\end{array}$ & $\begin{array}{l}\text { O papel da tradução } \\
\text { pedagógica à luz do Quadro } \\
\text { Comum Europeu de } \\
\text { Referência para as Línguas: } \\
\text { Aprendizagem, Ensino, } \\
\text { Avaliação. }\end{array}$ & $\begin{array}{l}\text { Realizar a técnica de skimming } \\
\text { e scanning no documento } \\
\text { "Quadro Comum Europeu de } \\
\text { Referência para as Línguas: } \\
\text { Aprendizagem, Ensino, } \\
\text { Avaliação". Sugere-se fazer } \\
\text { uma busca no documento } \\
\text { usando o termo "tradução" } \\
\text { como palavra-chave. }\end{array}$ & $\begin{array}{l}\text { Completar } 2 \text { provas curtas } \\
\text { (uma usando a técnica de } \\
\text { skimming e, a outra, de } \\
\text { scanning). }\end{array}$ \\
\hline $\begin{array}{l}\text { Semana } \\
2\end{array}$ & $\begin{array}{l}\text { O papel da tradução } \\
\text { pedagógica na aquisição de } \\
\text { línguas estrangeiras. }\end{array}$ & $\begin{array}{l}\text { Realizar a leitura de "The Role } \\
\text { of Pedagogical Translation in } \\
\text { Second Language Acquisition" } \\
\text { e "Aplicaciones prácticas de la } \\
\text { traducción pedagógica en la } \\
\text { clase de ELE". }\end{array}$ & $\begin{array}{l}\text { Fórum 1: Em grupos, formular } \\
\text { perguntas problematizadoras } \\
\text { sobre o uso da tradução } \\
\text { pedagógica nas salas de aulas } \\
\text { costarriquenhas. }\end{array}$ \\
\hline $\begin{array}{l}\text { Semana } \\
3\end{array}$ & $\begin{array}{l}\text { O papel da tradução à luz do } \\
\text { Estado da Educação }\end{array}$ & $\begin{array}{l}\text { Realizar a técnica de } \\
\text { identificação de ideias centrais } \\
\text { no documento "El } \\
\text { Estado de la Educación". }\end{array}$ & $\begin{array}{l}\text { Participar no } 2^{\circ} \text {. Fórum (10) } \\
\text { Entrega da primeira parte do } \\
\text { ensaio }(10 \%)\end{array}$ \\
\hline $\begin{array}{l}\text { Semana } \\
4\end{array}$ & $\begin{array}{l}\text { O papel da tradução } \\
\text { pedagógica para o } \\
\text { desenvolvimento das } \\
\text { competências comunicativas } \\
\text { no ensino-aprendizagem de } \\
\text { inglês. }\end{array}$ & $\begin{array}{l}\text { Realizar a leitura de "Revisión } \\
\text { Destrezas más allá de la } \\
\text { Escuela en Costa Rica". }\end{array}$ & $\begin{array}{l}\text { Criar um glossário de termos e } \\
\text { conceitos novos. }\end{array}$ \\
\hline $\begin{array}{l}\text { Semana } \\
5\end{array}$ & $\begin{array}{l}\text { O papel da tradução } \\
\text { pedagógica para o } \\
\text { desenvolvimento das } \\
\text { competências comunicativas } \\
\text { no ensino-aprendizagem de } \\
\text { inglês. }\end{array}$ & $\begin{array}{l}\text { Realizar a leitura de } \\
\text { "Pautas para la } \\
\text { elaboración de un } \\
\text { programa de traducción } \\
\text { técnica básica para } \\
\text { instituciones } \\
\text { vocacionales". }\end{array}$ & $\begin{array}{l}\text { Apresentação e análise de um } \\
\text { plano de aula no qual se } \\
\text { utilize a tradução como } \\
\text { método de ensino ( } 20 \%) \\
\text { Entrega da segunda parte do } \\
\text { ensaio }(10 \%)\end{array}$ \\
\hline $\begin{array}{l}\text { Semana } \\
6\end{array}$ & & & Entrega final do ensaio (30\%) \\
\hline
\end{tabular}




\begin{tabular}{|c|c|c|}
\hline & Avaliação & \\
\hline & Provas curtas & $\begin{array}{l}10 \%(5 \% \\
\text { cada uma })\end{array}$ \\
\hline & $\begin{array}{l}\text { Duas entregas parciais } \\
\text { do ensaio }\end{array}$ & $20 \%$ \\
\hline & Dois fóruns & $15 \%$ \\
\hline & Elaboração de um wiki & $15 \%$ \\
\hline & $\begin{array}{l}\text { Análise de um plano de } \\
\text { aula }\end{array}$ & $20 \%$ \\
\hline & Entrega do ensaio & $20 \%$ \\
\hline
\end{tabular}

\section{Bibliografia}

ALCARAZO, Noelia. e LÓPEZ, Nuria. Aplicaciones prácticas de la traducción pedagógica en la clase de ELE. Revista electrónica de didáctica del español lengua extranjera ,n.26, p. 1-15. Disponível em: $<<$ http://www.mecd.gob.es/dctm/redele/Material-RedEle/Revista/2014_26/2014_ redELE_26_00ALCARAZO-LOPEZ.pdf?documentId=0901e72b818b47ad >>

ALVARADO, Georgina.. En una silla de ruedas de Carmen Lyra: La traducción inversa como una reescritura funcional (Dissertação de Mestrado). Universidade Nacional, Heredia. Disponívem em: $<<$ http://www.mogap.net/pmt/georginaalvarado.pdf $>>$

ÁLVAREZ-GALVÁN, José Luís. A skills beyond school review of Costa Rica (Series: OECD Reviews of Vocational Education and Training). Disponível em: <<https://doi.org/10.1787/9789264233256en $>$

BARCLAY, J. Richard.; BRANSFORD, John; FRANKS, Jeffery; MCCARRELL, Nancy e NITSCH, Kathy. Comprehension and semantic flexibility. Journal of Verbal Learning and Verbal Behavior, $\mathrm{n}$. 13, 1974. Disponível em: << https://doi.org/10.1016/S0022-5371(74)80024-1〉>

BRANDSFORD, J. D. e JOHNSON, M. K. Contextual prerequisite for understanding: Some investigations of comprehension and recall 1. Journal of Verbal Learning and Verbal Behavior, n. 11, p. 717-726, 1972. Disponível em: <<https://doi.org/10.1016/S0022-5371(72)80006-9>>

COLINA, Sonia. Translation Teaching from Research to the Classroom A Handbook for Teachers. Boston: McGraw Hill, 2003.

COOK, Vivian. Second Language Learning and Language Teaching ( $4^{\mathrm{a}}$ ed.). London: Hodder Education, 2008.

COUNCIL FOR CULTURAL COOPERATION EDUCATION COMMITTEE. Common European Framework of Reference for Languages: Learning, Teaching, Assessment. New York: Cambridge University Press, 2001. Disponível em: $<<$ http://www.coe.int/t/dg4/linguistic/Source/Framework_EN.pdf $>>$ 
DELISLE, Jean. Translation: An Interpretative Approach. Ottawa: University of Ottawa Press, 1988.

(ed).. Enseignement de la traduction et traduction dans l'Enseignement. Ottwa: Les Presses de l’Université d'Ottawa, 1998. Disponível em: << https://doi.org/10.26530/OAPEN_579204>>

DOUGLAS, Susan e CRAIG, Samuel. Collaborative and Iterative Translation: An Alternative Approach to Back Translation. Journal of International Marketing, n.15, p.30-43, 2007. Disponível em: $<<$ https://doi.org/10.1509/jimk.15.1.030>>

ESCOBAR, Antonio. Pautas para la elaboración de un programa de traducción técnica básica para instituciones vocacionales. Heredia: UNA, 2009.

GALAN-MAÑAS, Anabel. Enseñanza de la iniciación a la traducción basada en competencias: Resultados de una validación empírica. Horizontes de Lingüística Aplicada, n.12, p.123-148, 2013.Disponívem em: $<<$ http://periodicos.unb.br/index.php/horizontesla/article/view/9952/8797>>

GRIFFIN, Frank. Idioms and Back Translation. Business Communication Quarterly, n. 67, p.455-464, 2004. Disponível em:<<_https://doi.org/10.1177/1080569904270987>>

HERNÁNDEZ, María Rosa. La traducción pedagógica en la clase de E/LE. En Actas ASELE. Disponível em: <<https://cvc.cervantes.es/ensenanza/ biblioteca_ele/asele/pdf/07/07_0247.pdf〉>

HURTADO, Amparo. La enseñanza de la traducción. España: Publicaciones de la Universitat Jaume I, 1996.

KELLY, Dorothy. A Handbook for Translation Trainers. Nova York: Routledge, 2005.

LEONARDI, Vanessa. The role of pedagogical translation in second language acquisition. Bern: Peter Lang. Disponível em: << https://doi.org/10.3726/978-30351-0071-6>>

PINTADO, Lucía. Fundamentos de la traducción pedagógica: Traducción, pedagogía y comunicación. Sendebar,n.23, p.321-353, 2012. Disponível em:

<<http://revistaseug.ugr.es/index.php/sendebar/article/view/41/41>>

SALEM, Ilana. L1-L2 sentence translation in classroom grammar tests. ELT Journal, n. 66, p.147-155, 2012. Disponível em: << https://doi.org/10.1093/elt/ccr044>>

ZHANG, Yun. e GAO, Can. (2014). Back Translating: An Integrated Approach to Focus Learners`Attention on Their L2 Knowledge Gaps. English Teaching Forum, n. 52, p.30-35, 2014. Disponível em: <<http://perpustakaan.unitomo.ac.id/repository/52_1_6_zhang_gao.pdf>> 